\title{
Policy recommendations and cost implications for a more sustainable framework for European human biomonitoring surveys
}

Anke Joas $^{\text {a,* }}$, Lisbeth E. Knudsen ${ }^{c}$, Marike Kolossa-Gehring ${ }^{\text {b }}$, Ovnair Sepai ${ }^{\mathrm{m}}$, Ludwine Casteleyn $^{\mathrm{f}}$, Greet Schoeters ${ }^{\mathrm{d}, \mathrm{z}}$, Jürgen Angerer ${ }^{\mathrm{e}}$, Argelia Castaño ${ }^{\mathrm{j}}$, Dominique Aerts ${ }^{\mathrm{g}}$, Pierre Biot ${ }^{\mathrm{g}}$, Milena Horvat ${ }^{\mathrm{q}}$, Louis Bloemen ${ }^{\mathrm{i}}$, M. Fátima Reis ${ }^{\mathrm{w}}$, Ioana-Rodica Lupsa ${ }^{\mathrm{u}}$, Andromachi Katsonouri ${ }^{\mathrm{s}}$, Milena Cerna ${ }^{\mathrm{k}}$, Marika Berglund ${ }^{\mathrm{h}}$, Pierre Crettaz ${ }^{1}$, Peter Rudnai ${ }^{\mathrm{x}}$, Katarina Halzlova ${ }^{\mathrm{n}}$, Maurice Mulcahy ${ }^{\mathrm{v}}$, Arno C. Gutleb ${ }^{\mathrm{p}}$, Marc E. Fischer ${ }^{\circ}$, Georg Becher ${ }^{\mathrm{aa}}$, Nadine Fréry ${ }^{\mathrm{ab}}$, Genon Jensen ${ }^{\mathrm{ac}}$, Lisette Van Vliet ${ }^{\mathrm{ac}}$, Holger M. Koch ${ }^{\mathrm{e}}$, Elly Den Hond ${ }^{\mathrm{d}}$, Ulrike Fiddicke ${ }^{\mathrm{b}}$, Marta Esteban ${ }^{\mathrm{j}}$, Karen Exley ${ }^{\mathrm{m}}$, Gerda Schwedler $^{\mathrm{b}}$, Margarete Seiwert ${ }^{\mathrm{b}}$, Danuta Ligocka ${ }^{\mathrm{r}}$, Philipp Hohenblum ${ }^{\text {ah }}$, Soterios Kyrtopoulos ad, Maria Botsivali ${ }^{\text {ad }}$, Elena DeFelip ${ }^{\text {ae }}$, Claude Guillou ${ }^{\text {af }}$, Fabiano Reniero ${ }^{\text {af }}$, Regina Grazuleviciene ${ }^{\text {ai }}$, Toomas Veidebaum ${ }^{\text {aj }}$, Thit A. Mørck ${ }^{c}$, Jeanette K.S. Nielsen ${ }^{c}$, Janne F. Jensen ${ }^{c}$, Teresa C. Rivas ${ }^{j}$, Jinny Sanchez ${ }^{j}$, Gudrun Koppen ${ }^{d}$, Roel Smolders ${ }^{\mathrm{d}}$, Szilvia Kozepesy ${ }^{\mathrm{x}}$, Adamos Hadjipanayis ${ }^{\mathrm{y}}$, Andrea Krskova ${ }^{\mathrm{k}}$,

Rory Mannion ${ }^{v}$, Marek Jakubowski ${ }^{\mathrm{r}}$, J. Aleksandra Fucic ${ }^{\mathrm{ag}}$, Jose Pereira-Miguel ${ }^{\mathrm{w}}$, Anca E. Gurzau ${ }^{\mathrm{u}}$, Michal Jajcaj ${ }^{\mathrm{n}}$, Darja Mazej ${ }^{\mathrm{q}}$, Janja Snoj Tratnik ${ }^{\mathrm{q}}$, Andrea Lehmann ${ }^{1}$, Kristin Larsson ${ }^{\mathrm{h}}$, Birgit Dumez ${ }^{\mathrm{f}}$, Reinhard Joas ${ }^{\mathrm{a}}$

a BiPRO, Germany

${ }^{\mathrm{b}}$ Federal Environment Agency (UBA), Germany

' University of Copenhagen, Denmark

${ }^{\mathrm{d}}$ VITO, Environmental Risks and Health Unit, Belgium

e Institute for Prevention and Occupational Medicine of the German Social Accident Insurance-Institute of the Ruhr-Universität Bochum (IPA), Germany

${ }^{\mathrm{f}}$ KU LEUVEN, University of Leuven, Belgium

${ }^{g}$ Federal Public Service Health, Food Chain Safety and Environment, Belgium

${ }^{\mathrm{h}}$ National Institute of Public Health, Czech Republic

${ }^{i}$ Environmental Health Sciences International, The Netherlands

${ }^{j}$ Environmental Toxicology, CNSA-Instituto de Salud Carlos III, Spain

${ }^{\mathrm{k}}$ National Institute of Public Health, Czech Republic

${ }^{1}$ Federal Office of Public Health (FOPH), Switzerland

m Public Health England, United Kingdom

${ }^{\mathrm{n}}$ Urad Verejneho Zdravotnictva Slovenskej Republiky, Slovakia

o Laboratoire National de Santé, Luxembourg

${ }^{\mathrm{p}}$ Centre de Recherche Public - Gabriel Lippmann, Luxembourg

${ }^{\mathrm{q}}$ Jožef Stefan Institute, Slovenia

${ }^{\mathrm{r}}$ Nofer Institute of Occupational Medicine, Poland

s State General Laboratory, Cyprus

${ }^{\mathrm{u}}$ Environmental Health Center, Romania

${ }^{v}$ Health Service Executive, Ireland

${ }^{\mathrm{w}}$ Medical Faculty of the University of Lisbon, Portugal

${ }^{x}$ National Institute of Environmental Health, Hungary

yarnaca General Hospital, Ministry of Health, School of Medicine, European University of Cyprus, Cyprus

${ }^{\mathrm{z}}$ University of Antwerp, Belgium, Southern Denmark University, Denmark

aa Norwegian Institute of Public Health, Norway

${ }^{\mathrm{ab}}$ French Institute for Public Health Surveillance, France

${ }^{a c}$ Health and Environment Alliance, Brussels

ad National Hellenic Research Foundation, Greece

ae National Institute for Health, Italy

af European Commission, Joint Research Centre (JRC), Institute for Health and Consumer Protection (IHCP), Italy

ag Institute for Medical Research and Occupational Health, Croatia

${ }^{\text {ah }}$ Federal Environment Agency, Austria

ai Vytautas Magnus University, Lithuania

aj National Institute for Health Development, Estonia

* Corresponding author. 


\section{A R T I C L E I N F O}

\section{Article history:}

Received 12 June 2014

Received in revised form

8 October 2014

Accepted 9 October 2014

\section{Keywords:}

HBM

Policy

European platform

Decision scheme

Prioritisation

Resources

\begin{abstract}
A B S T R A C T
The potential of Human Biomonitoring (HBM) in exposure characterisation and risk assessment is well established in the scientific HBM community and regulatory arena by many publications. The European Environment and Health Strategy as well as the Environment and Health Action Plan 2004-2010 of the European Commission recognised the value of HBM and the relevance and importance of coordination of HBM programmes in Europe. Based on existing and planned HBM projects and programmes of work and capabilities in Europe the Seventh Framework Programme (FP 7) funded COPHES (COnsortium to Perform Human Biomonitoring on a European Scale) to advance and improve comparability of HBM data across Europe. The pilot study protocol was tested in 17 European countries in the DEMOCOPHES feasibility study (DEMOnstration of a study to COordinate and Perform Human biomonitoring on a European Scale) cofunded (50\%) under the LIFE + programme of the European Commission. The potential of HBM in supporting and evaluating policy making (including e.g. $\mathrm{REACH}$ ) and in awareness raising on environmental health, should significantly advance the process towards a fully operational, continuous, sustainable and scientifically based EU HBM programme. From a number of stakeholder activities during the past 10 years and the national engagement, a framework for sustainable HBM structure in Europe is recommended involving national institutions within environment, health and food as well as European institutions such as ECHA, EEA, and EFSA. An economic frame with shared cost implications for national and European institutions is suggested benefitting from the capacity building set up by COPHES/DEMOCOPHES.
\end{abstract}

(c) 2014 Elsevier Inc. All rights reserved.

\section{Introduction}

Increasing public environmental health interest and awareness has developed over the past 20 years from concerns of the (general) public, regulators, and non-governmental organisations (NGOs) about rising incidence rates for a number of important diseases, and the potential risks of exposure to environmental stressors (e.g. endocrine disruptors) for human reproduction and health. As a consequence a better understanding of the health and environment relationships is asked for, and requests for collective as well as individual data on exposure that could be used for risk assessment and management are constantly growing.

To reduce potential risks a considerable number of regulatory measures has been taken on EU level in particular for chemicals, which requires health risk assessment for workers and the general population. A better understanding of determinants of health is also required to improve effective health promotion and disease preventive policies and to reduce public health costs.

Human biomonitoring (HBM) surveys can be used to establish baseline levels of chemicals in the investigated population, to compare exposures and to help identify priority chemicals for which further action should be taken. An important field is use of HBM in policy surveillance, identification of new risks, and benefits for risk assessment and chemicals regulation (Kolossa-Gehring, 2012).

HBM is a growing discipline used for exposure and risk assessment in environmental and occupational health (Manno et al., 2010; Angerer, 2012; Knudsen and Merlo, 2012). In environmental health, a number of studies have been performed with newborns (Casas et al., 2013; Leventakou et al., 2014; Pedersen et al., 2013; Papadopoulou et al., 2013)), children (Frederiksen et al., 2014; Mørck et al., 2014a; Conrad et al., 2010), and adults with classical biomarkers of exposure (Bevan et al., 2013; De Felip et al., 2014) as well as promising markers of effect (Stayner et al., 2014; Pedersen et al., 2013; Merlo et al., 2014; Silins and Hogberg, 2011) and new 'omics' techniques (Knudsen and Merlo, 2012; Hebels et al., 2013; Vrijheid et al., 2014; Kyrtopoulos, 2013; Vineis et al., 2013).

Several EU financed projects have developed and validated human biomarkers such as the PHIME (Public Health Impact of long-term, low-level Mixed element Exposure in susceptible population strata) integrated project, Newgeneris (Newborns and Genotoxic exposure risks: Development and application of biomarkers of dietary exposure to genotoxic and immunotoxic chemicals and of biomarkers of early effects, using mother-child birth cohorts and biobanks) programme (Merlo et al., 2009), or the ECNIS (Environmental Cancer Risk, Nutrition and Individual Susceptibility) network of excellence or OBELIX (Obesogenic endocrine disrupting chemicals: linking prenatal exposure to the development of obesity later in life).

HBM activities in Canada, France, Belgium (Flanders), Germany, India, and Romania have been described in the textbook issued in 2011 (Knudsen and Merlo, 2012) when activities were also known in countries as Austria (Hohenblum et al., 2012), Czech Republic (Cerná et al., 2012), Poland (Jakubowski and Trzcinka-Ochocka, 2005), Sweden (Bergkvist et al., 2010), and US (CDC, 2010).

HBM data can be used to determine whether the level of exposure of the public, special subgroups or individuals are acceptable or whether measures need to be taken. HBM can be used to monitor whether bans on substances or restrictions on their use have led to a decrease in exposure, and HBM can provide information on substance properties and potential risks.

But European countries differ largely in their priority setting, environmental concerns, registration governance, culture and ethics, as well as in their resources in terms of budget, manpower and expertise and there is a severe lack of comparable data and coherent approach within the European Union. Fragmentation between countries and studies however, strongly limits the use of results for European health impact assessments and cross-border comparison as well as the evaluation of key European chemicals, and customers policies. To allow a better use of the data and to evaluations at European scale and international scale, harmonisation of activities has been considered to be required urgently (Joas et al., 2012).

Therefore in 2003 the European Commission and the European Member States (MS) started efforts to construct an efficient HBM framework across the European Union within the European Environment \& Health Strategy (SCALE) and in particular the Environment and Health Action Plan for Europe (EHAPE 2004-2010). As a result a preparatory feasibility study (ESBIO) was conducted from 2005-2007 (Viso et al., 2009; Joas et al., 2012) that discussed 
the pros and cons of a harmonised approach in the EU in close collaboration with the EU Parliament and a consultative forum (CF), that was set up in 2002 as the stakeholder consultation body for the development of SCALE, and that continued to provide input into the implementation of the EHAPE. The consultative forum consisted of environment and health representatives of EU Member States as well as experts from NGOs, industry and EU and international bodies (European Food Safety Authority (EFSA), World Health Organisation (WHO), etc.). Due to the close collaboration with the consultative forum and in particular with the MS experts the first key steps for a coordinated approach could be achieved. Based on the work of ESBIO (Reis et al., 2007), discussions within the $\mathrm{CF}$ and a number of supportive reports such as the midterm evaluation report of the EHAPE (Commission of the European Communities, 2007), the pilot phase for harmonised HBM in Europe was started with the Consortium to Perform Human Biomonitoring on a European Scale (COPHES) in 2009, that laid the basis for a first feasibility study DEMOCOPHES (DEMOnstration of a study to COordinate and Perform Human biomonitoring on a European Scale) starting in 2010.

The main objective of COPHES/DEMOCOPHES was the development of a functional framework for a coherent approach to HBM in Europe in order to achieve comparable HBM data that support environmental, health and chemicals policy (Joas et al., 2012). Major results from COPHES/DEMOCOPHES are detailed in this special volume.

This paper discusses the results of the policy work that was destined to develop recommendations for a strategy for future HBM activities in the EU, to elaborate a draft concept for a sustainable EU HBM infrastructure supporting the future implementation of HBM and its use as a tool to inform policy making with comparable and reliable results that are necessary for European policy making and global initiatives. It further aimed at providing a first estimate of costs, benefits and resources needed for a sustainable HBM initiative.

\section{Methods}

The development of the proposal for a sustainable EU HBM infrastructure built on knowledge gained from ESBIO and on intensive stakeholder consultation. In addition, it built on input from Member States, European authorities (Commission and agencies such as EFSA, the European Chemicals Agency (ECHA), and the European Environment Agency (EEA) and of the World Health Organisation Europe (WHO-Europe) regarding requirements and needs related to HBM and experiences with costs, benefits and its practical application as a surveillance tool in policy making.

The project team on policy support asked for and welcomed feedback from environment and health authorities at a national level in all Member States, Directorates General of the European Commission for Health, Environment, Occupation and Enterprise as well as its related European Agencies, and of the WHO European Centre for Environment and Health. In addition, input was provided by invited stakeholders from the European non-governmental organisation Health and Environment Alliance (HEAL), from the European association of chemical industry (CEFIC), from international well established national HBM programmes namely the National Health and Nutrition Survey in the USA and the Canadian Health Measures Survey (CHMS) in Canada, and from related European research projects. Invitation was based on political relevance and thematic expertise in environmental or environmental health issues.

\subsection{Data collection for identification of needs and priorities}

Collection of policy needs was based on literature search, evaluation of existing regulation and infrastructure and stakeholder involvement. Information collected via these means was complemented by evaluation of personal interviews.

\subsubsection{Identification of needs and priorities of Member States and study leaders via electronic questionnaire}

Key needs and currently existing practise, expectations, benefits, operational issues, and remaining questions related to the use of HBM as a policy tool have been collected via questionnaires from competent authorities (Ministries of Health and Ministries of Environment) and other stakeholders (scientific study leaders, study leaders of the DEMOCOPHES pilot study and the experts responsible for carrying out the pilot study in the individual countries) and via literature search. The survey with questions about current use of HBM, expectations, benefits, operational issues, and key needs related to the use of HBM as policy tool was disseminated to several hundred institutions in 28 European Member States and adjacent countries. Responses were received from more than 100 experts from the institutions listed in (Table 1).

\subsubsection{Identification of needs and priorities by means of consultations} with scientific experts, policy makers and stakeholders

For further information exchange on priorities and needs, promotion of a common understanding of the potential role of HBM and preparation of the concept for a sustainable HBM framework in Europe, the COPHES work package leaders on policy advice and other Work package leaders participated in international conferences targeted on HBM allowed to promote the European harmonisation

- The Fifth Ministerial Conference on Environment and Health "Protecting children's health in a changing environment" organised by the World Health Organisation (WHO) Europe in March 2010 which resulted in the Parma Declaration on Environment and Health

- The International Conference on Human Biomonitoring -"Political benefits - scientific challenges", organised by the German Ministry of Environment (BMU) and the Federal Environment Agency (UBA) in Berlin, in September 2010.

- The European Conference "From human biomonitoring to policy: a sustainable 'marriage' between health and environment" organised by the Environment, Nature Energy Department of the Flemish government under the Belgian Presidency of the European Union in October 2010

Three dedicated stakeholder workshops have been organised by the COPHES team on policy advice during the course of 2011 and 2012 (see http://www.eu-hbm.info/cophes/project-workpackages/wp8-support-eu-hbm-programme). Meeting results have been compiled in project deliverables.

1. An EU Decision Makers Meeting on the use of Human Biomonitoring for policy making that took place in Munich on 4 May 2011.

2. A European Authorities Scientific Expert Meeting on the use of Human Biomonitoring as a policy tool on mid and long-term perspective (5-15 years) held in Brussels on 2 February 2012.

3. An international conference From Human Biomonitoring to European and national policies: meeting the Member States (MS) representatives organised in Paris at the Ministry of Health on 17 September 2012. 
Table 1

List of participating European Research Institutions and Authorities.

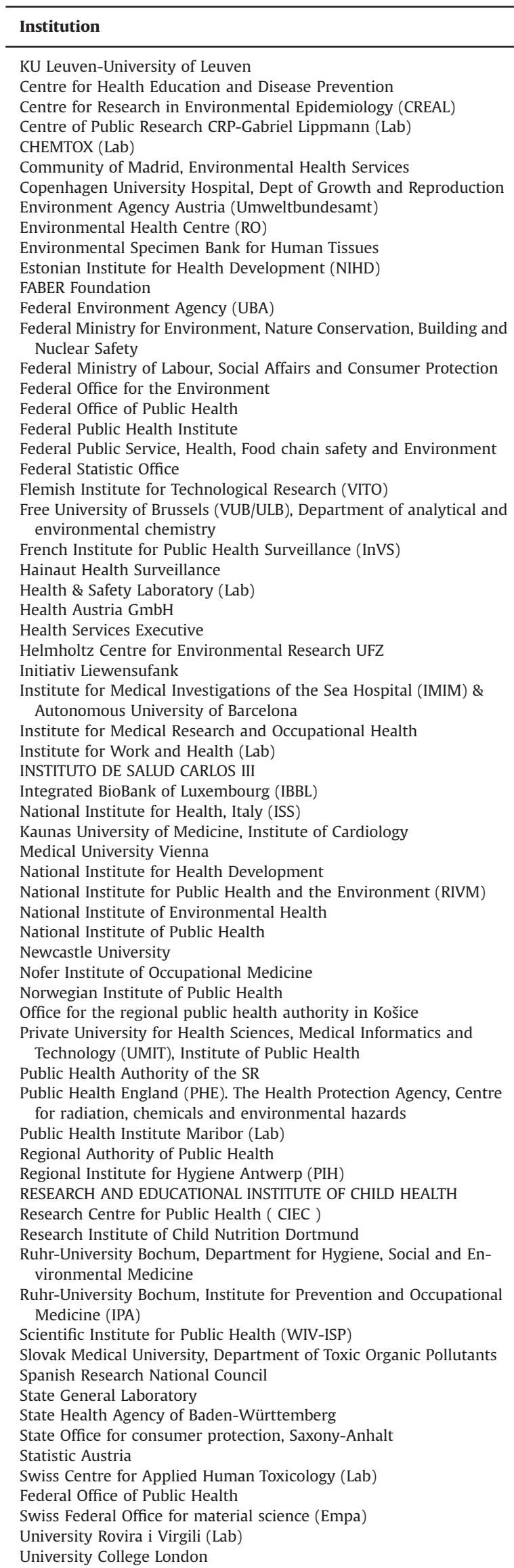

Table 1 (continued)

Country

BE

LT

LU

ES

DK

RO

$\mathrm{DE}$

AT

$\mathrm{CH}$

DE

BE

$\mathrm{BE}$ 2012).

\begin{tabular}{ll}
\hline Institution & Country \\
\hline University Medical Centre Ljubljana, Institute of Clinical Chemistry & SI \\
and Biochemistry (Lab) & DK \\
University of Copenhagen & DE \\
University of Erlangen, Institute of Occupational, Social and En- & \\
vironmental Medicine ( IPASUM) & ES \\
University of Las Palmas de Gran Canaria & BE \\
University of Liege, Department of Toxicology & PT \\
University of Lisbon, Institute of Preventive Medicine & SI \\
University of Ljubljana, Jožef Stefan Institute & CY \\
University of Nicosia & DE \\
University of Southern Denmark & SE \\
University of Stockholm, Institute of Environmental Medicine, Kar- & \\
olinska Institute & AT \\
University of Vienna, Department of Medical Genetics & AT \\
University of Vienna, Institute of Environmental Health & AT \\
University of Vienna, Institute of Nutritional Sciences & AT \\
University of Vienna, Institute of Public Health & LT \\
University of Vilnius & LT \\
Vytautas Magnus University Kaunas; Department for Environmental & \\
Studies & \\
\hline
\end{tabular}

Invitations to participate in the discussion were sent to different departments (units) of the Directions General of Enterprise, Employment, Environment, Health and Consumers and Research and Innovation, the Joint Research Centre (JRC), as well as to European Agencies (ECHA, EEA, EFSA, EMA, OSHA) and Scientific Committees. Overall 17 Commission services actively supported the process by participating in the meetings (Table 2).

In addition, various departments of the Ministries of Health and of Environment as well as corresponding national agencies or institutes were contacted in all 28 European Member States plus associated European countries such as Norway, Switzerland, and Iceland Representatives from 12 countries participated in the discussion process. Bilateral contacts and information exchange took place with the chemicals Unit at the European Commission Directorate General for Environment (March 2011 and 2012, July 2012), with the Risks assessment and Health information Units at the Directorate General for Health and Consumers at the European Commission (March 2012, September 2012) and with public health agencies in Canada and the USA (October 2011, April 2012, Sep 2012) as well as with Ministries of Health and Environment in interested Member States (e.g. France, Germany).

COPHES work package on policy support supported the development of the WHO mercury survey (Egorov et al., 2013) and close consultations and exchange were organised with the WHO Regional Office for Europe, European Centre for Environment and Health, Bonn Office (Sep 2011, Feb 2012, April 2012, Sep 2012, Oct

Furthermore, intensive exchange was realised with related European research projects such as the European Health Examination Surveys (EHES) via exchange with the Finnish National Institute for Health and Welfare (THL) as Project Management (March 2010, 2011, 2012, April 2012) or ERA-ENVHEALTH (June 2012) via the French agency for food, environmental and occupational health safety (ANSES) as coordinating beneficiary. Finally, continued exchange was sought with PHIME, ENVIROGENOMARKERS, and ECNIS via the COPHES work package leader on horizon scanning.

The COPHES team on policy advice participated in the public consultations related to the drafting of the 7th Environment Action Plan (June 2012), drafted a vision paper for future use of HBM and a number of discussion documents for better integration of HBM in a number of public health and environmental policies, participated in international conferences and final meetings of EHES and 
Table 2

List of participating European Institutions and WHO.

\begin{tabular}{|c|c|}
\hline Institution & Active participation \\
\hline \multirow[t]{2}{*}{ DG Enterprise } & Unit G.1, Chemicals-REACH \\
\hline & Unit G.2, Chemicals-Classification and Labelling \\
\hline \multirow[t]{2}{*}{ DG Environment } & Unit D.3, Chemicals, Biocides and Nanomaterials \\
\hline & Unit F.4, Research and Innovation \\
\hline \multirow[t]{8}{*}{ European Commission General Directorate Health and Consumers } & Unit B.3 Product and Service safety \\
\hline & Unit C.2, Health information \\
\hline & Unit C.3, Health threats \\
\hline & Unit D.3, Risk assessment \\
\hline & European Agency for Health and Consumers (EAHC) \\
\hline & Scientific Committee on Health and Environmental Risks (SCHER) \\
\hline & Scientific Committee on Consumer Safety (SCCS) \\
\hline & Scientific Committee on Emerging and Newly Identified Health Risks (SCENIHR) \\
\hline DG Research & Unit I.4, Climate Change and natural hazards \\
\hline EEA, European Environment Agency- & Unit IEA1, Integrated Environmental Assessments-Major integrated assessments \\
\hline \multirow[t]{2}{*}{ JRC, Joint Research Centre- } & Chemical Assessment and Testing (CAT) Unit \\
\hline & Systems toxicology \\
\hline EFSA, European Food Safety Authority & Unit of Contaminants (CONTAM) \\
\hline WHO & WHO European Centre for Environment and Health \\
\hline
\end{tabular}

ERA-ENVHEALTH and participated at the Final project meeting of the pilot projects and the international conference "Human Biomonitoring (HBM) Linking Environment to Health and Supporting Policy" under the Cypriot presidency in Cyprus 22-24 October 2012.

Throughout the whole process consensus was sought between the participating stakeholders and comments and suggestions were taken into account as far as possible in the elaboration of the concept. It has to be mentioned however, that the outcome of the discussion process was influenced by the active participation in the process.

2.2. Methodology for elaboration of concept for sustainable organisation and structure of an EU HBM network in Europe

The elaboration of the concept was based on the reported needs of policy makers as well as experiences of countries with established HBM programmes such as France (Fréry et al., 2012), Czech Republic (Cerna et al., 2012) and Germany (Kolossa-Gehring et al., 2012), Slovenia (Perharic and Vracko, 2012) of regions such as Flanders (Schoeters et al., 2012),and other European countries. Comprehensive HBM programmes from other regions in the world namely USA and Canada were particularly taken into account. In addition, experiences and recommendations from the pilot project on harmonisation of health examination surveys in Europe (EHES) were taken into account and potential synergies in the light of associated costs were considered (see Section 3.3.3).

The proposal for sustainable infrastructure for HBM in Europe and a first estimation of related costs was made (Section 3.4). This includes links to the existing regulatory frameworks (Section 3.5) and recommendations for coordinated support to policy decision making (Section 3.6).

2.3. Methodology for estimation of costs and resources, needed for a sustainable long-term European HBM

Based on the experiences from DEMOCOPHES and the concept of a sustainable framework data collection and calculation of budgetary ranges have been structured into the following categories:

- European Platform for systematic selection of HBM candidate substances

- European Decision making process
- The national surveillance infrastructure with national Focal Point, regional and local executing units, qualified laboratories, national data interpretation units, and national communication units

- European HBM implementation network developing guidance on study protocol, quality assurance system for laboratory data, data management and interpretation unit, and communication as well as

- Financial and organisational mechanisms

- Review mechanisms and continuous improvement of the network

For the estimation of costs and resources needed each of the above mentioned aspects has been considered in a minimal as well as in a maximal scenario. Man power and related costs have been calculated on average salaries. Finally, each parameter has been checked for its sensitivity.

Based on the sustainable framework structure, the existing data and Member State experiences an Excel tool has been developed to centralize and efficiently store and make use of the data. The Excel file is composed of 14 data sheets. All sheets are connected to one sheet comprising an overview on the overall costs.

In general, the sheets present three main columns, namely "Investment costs", "Recurrent expenditure" and "Variable costs". The column "Investment costs" summarises the costs needed as non-recurrent expenses to e.g. establish structures, studies or personnel/positions. "Recurrent expenditures" calculates unavoidable and periodical costs, e.g. costs for the maintenance of the platform, a website, etc. "Variable costs" comprises the costs that directly depend on decisions taken, e.g. number and type of substances, number of Member States participating, number of samples, etc.

The columns were further divided into the sub categories "time expenditure", "personnel costs" and "material expenditure". The sheets allow the input of information for single countries (Member States) as well as the other involved bodies. The rationale behind this procedure is to be able to collect data as detailed as possible to have justifiable results in the end.

\subsubsection{Data collection}

Background data for the calculation have been collected from DEMOCOPHES participants and national HBM programmes. As these data are sensitive, none of the data given in this report can be traced back to its origin. All 17 DEMOCOPHES implementing partners were contacted and condensed budgetary information 
Table 3

DEMOCOPHES partners approached for financial information.

\begin{tabular}{|c|c|c|c|}
\hline $\begin{array}{l}\text { Participant } \\
\text { country }\end{array}$ & MS & Supporting ministry & Performing institutions \\
\hline Belgium & $\mathrm{BE}$ & $\begin{array}{l}\text { Health, Food and } \\
\text { Environment }\end{array}$ & $\begin{array}{l}\text { Governmental Institutes, } \\
\text { Private and University }\end{array}$ \\
\hline Cyprus & $\mathrm{CY}$ & Health & Governmental Institute \\
\hline Germany & $\mathrm{DE}$ & Environment & Governmental institute \\
\hline Denmark & DK & $\begin{array}{l}\text { Environment, Food, } \\
\text { Health }\end{array}$ & University \\
\hline Poland & PL & Health & Governmental institute \\
\hline Romania & RO & Health & Private \\
\hline Slovenia & SI & Health & Governmental institute \\
\hline Spain & ES & Environment & Governmental institute \\
\hline Hungary & $\mathrm{HU}$ & $\begin{array}{l}\text { Health and } \\
\text { environment }\end{array}$ & Governmental institute \\
\hline Sweden & SE & Environment & University \\
\hline United Kingdom & UK & Health & Governmental institute \\
\hline Portugal & PT & Health & Governmental institute \\
\hline Ad hoc & $\mathrm{CH}$ & Health & Governmental institute \\
\hline Czech Republic & $\mathrm{CZ}$ & Health & Governmental institute \\
\hline Slovakia & SK & Health & Governmental institute \\
\hline Luxembourg & LU & Health & Private \\
\hline Ireland & IE & Health & Governmental institute \\
\hline Adhoc & FR & Health & Governmental institute \\
\hline Adhoc & $\mathrm{AU}$ & Environment & Governmental institute \\
\hline Adhoc & CROA & Health & Governmental institute \\
\hline Ad hoc & NO & Health & Governmental institute \\
\hline
\end{tabular}

was provided by 12 of the 17 countries (i.e. $\mathrm{CH}, \mathrm{CZ}, \mathrm{DE}, \mathrm{DK}, \mathrm{IE}, \mathrm{LU}$, PT, RO, SE, SI, SK, UK). As the budget calculations for the pilot study are estimates only beneficiaries involved in the pilot study were asked for an adjustment of the delivered data, including in-kind contributions.

In parallel, the timesheets of all DEMOCOPHES implementing partners have been evaluated for efforts related to operational HBM framework, sampling, recruitment and sample collection, sample handling, chemical analysis and storing (including biobanking), data analysis and integrated interpretation as well as communication and dissemination and management (Table 3).

Beneficiaries with ongoing or finalised national HBM studies have been asked to kindly provide financial and time efforts accordingly. The request also included information about number of samples and substances covered in the national studies. For a plausibility check, budgetary information and experiences from other countries namely USA and Canada have been taken into account.

For the estimations it was assumed that an EU HBM network will perform one measurement round each year. As it is not realistic to calculate costs at this stage exactly for a selected number of chemicals and samples, calculations are done by personnel costs and estimated overall efforts. Costs for chemical analysis of individual samples are not included in the estimate. Such individual costs have been investigated in detail in 2004 in preparation of the pilot phase and are less than €20-50 per samples for heavy metals and range from $€ 20$ - $€ 500$ for organic chemicals according to recent information from WHO (World Health Organisation, 2012). In addition, synergies can be used for a number of substances.

\subsubsection{Resource estimates}

For managing incoming input and ad-hoc suggestions for candidate substances in the (electronic) suggestion platform we estimated resource needs of a half time up to a full time person per year based on experiences from other regulations and conventions (secretariat).

For the decision committee we based our calculation on minimum and maximum scenario for an expert group. For the minimum scenario the calculation is based on 10 experts and 2 annual meetings. The maximum scenario is based on an expert group of 40 experts and 4 meetings per year. For the meetings we assumed two meeting days and three days preparation and follow up each. For travel costs we calculated an average of $€ 300$ per travel day per person. These figures include decision making on European scale. They do not include costs for scientific committees elaborating substance dossiers. This will allow participation of at least one delegate per Member State on average, and based on experience from other conventions, allows for up to 10 decisions per meeting.

For the European coordination platform as part of the implementation and enforcement network we based calculations on a best estimate of 5-10 full time equivalents per year. Based on experiences from the pilot study this will enable further development of guidance for study design/protocol, data analysis and reporting, communication, interpretation and translation into policy exchange and on potential data storage. It does not comprise establishment and maintenance of QA/QC systems. For the HBM implementation and enforcement network the resource needs have been estimated based on the minimum and maximum resource needs from the pilot phase. A small reduction factor was introduced due to the fact that efforts to build up routines and structures as during the pilot phase will not be necessary anymore (Table 4).

A part time position up to one full and one part time position is estimated for the operational framework on national level per campaign based on input from the pilot phase. For sampling, recruitment and sample collection a half time up to two full time positions are assumed. This parameter is highly sensitive depending on the number of samples as well as on the study design and the experience of the staff involved. The same personnel efforts are assumed for sample handling and chemical analysis, again being highly sensitive depending on the number of chemicals measured. For data analysis and the integrated interpretation three person months per year up to a full time equivalent is assumed. Depending on the data volume this is again a highly sensitive parameter. For the communication again three person months per year up to a full time equivalent is assumed.

As best estimate for all involved staff (senior and junior scientist, field workers, administrative staff) an average salary of

Table 4

Estimation of resource needs.

\begin{tabular}{|c|c|c|c|c|c|}
\hline \multirow[t]{2}{*}{ Task (per country) } & \multirow[t]{2}{*}{ Person Month p.a. (PM) } & \multicolumn{2}{|c|}{ Range } & \multirow[t]{2}{*}{ estimated PM p.a. min } & \multirow[t]{2}{*}{ estimated PM p.a. max } \\
\hline & & from & to & & \\
\hline Operational framework & 14.7 & 7.7 & 19.1 & 6 & 18 \\
\hline Sampling and Recruitment\& Sample collection & 11.9 & 1.1 & 21.4 & 6 & 24 \\
\hline Sample handling, quality assurance and analysis & 14.8 & 3.9 & 31.6 & 6 & 24 \\
\hline Data analysis and integrated interpretation & 4.4 & 1.1 & 6.5 & 3 & 12 \\
\hline Communication \& Dissemination & 5.1 & 1.6 & 11.7 & 3 & 12 \\
\hline Management & 3.3 & 1.1 & 5.9 & & \\
\hline
\end{tabular}

p.a.=per annum (per year). 
Table 5

Overview on average salary of scientific and administrative staff in 14 countries participating in pilot phase by country in Euro.

Average salary for DEMOCOPHES staff Average salary for DEMOCOPHES staff

\begin{tabular}{ll}
\hline 4196.88 & 4647.34 \\
5220.14 & 6496.55 \\
6786.84 & 2733.68 \\
3371.25 & 1788.36 \\
3604.10 & 4354.17 \\
5080.57 & 5244.95 \\
5549.57 & 4857.46 \\
\hline
\end{tabular}

$5000 €$ per month (individual ranges $€ 2500-12,000$ ) has been assumed for the calculation of personnel costs (Table 5). It needs to be considered that this figure not only presents an average for all 28 European countries and for different education levels. While sampling might be performed by a nurse with low salary data interpretation might be carried out by a highly paid specialist.

\section{Results and discussion}

\subsection{Current status and remaining priorities and needs}

COPHES has established the first Europe wide harmonised protocol for HBM surveillance of the European population and together with DEMOCOPHES, provided results about the feasibility of a harmonised sampling and analysis approach including capacity building and knowledge transfer, but is limited with regard to the selected set of substances, matrices and sample size. On the way towards a final sustainable and powerful European wide human biomonitoring survey framework comparable to the American NHANES (Calafat, 2012) or the Canadian Health Measures Survey (Haines and Murray, 2012) further research and development work will be needed in order to reach a self-supporting concept as suggested and described in this report.

Priorities for the future comprise, in particular, the identification of appropriate biomarkers including the development of validated analytical (large-throughput) methods, and the development of a European approach for the derivation of statistically based reference values and health based HBM guidance values. Other aspects are appropriate information, education, communication and dissemination of study results, data storage and sample/data sharing.

\subsection{Needs to be covered and limitations to respect}

During the stakeholder consultation, an improved use of monitoring data generated within the European Union including better access for secondary use and better comparability was emphasised as an important objective in European environmental and health policies.

\subsubsection{Comparable, accessible and timely monitoring data}

Comparable monitoring data on European scale are considered as key parameter for use of HBM as policy tool. Scientist and policy makers repeatedly highlighted the need for comparable data generated throughout Europe, and it was agreed that there is basically only one reliable approach, which is a harmonised study protocol. The specific request for additional HBM data to follow up uncertainties regarding future exposure, expressed in the opinion of the European Committee for Risk Assessment (RAC) from 15 June 2012, related to the first ever proposed restriction of four classified phthalates (DEHP, DBP, BBP, and DIBP) in articles under
REACH. This, highlights the importance of this tool for decision making on chemicals and product regulation.

Priorities in policy making are a fast response to questions and the provision of timely answers on needs for acute actions. In order to ensure an efficient use of HBM data for policy making and evaluation, European authorities and Member State authorities need free and timely access to all monitoring data required for data interpretation. For this reason there is a need for an established infrastructure and overall guidance that can quickly react to arising threats and that is cross sectional in structure. In the light of technology and science development and newly arising questions over time, the secondary use of data and samples is a second priority for European Commission Services. In this context, it was clarified that constraints to access and secondary use of HBM data need to be solved in the light of European data needs.

\subsubsection{Mechanisms of priority substances and appropriate biomarkers}

In the light of the huge and constantly increasing number of chemicals on the European market, and the several thousands of substances to be registered or authorised under REACH and assessed for potential risks, it was stressed that HBM will only be able to fill its role in risk assessment if appropriate procedures to identify substances of priority for monitoring via HBM can be established. It was highlighted in expert discussions that in addition to actively selected substances from regulatory processes it will be necessary to foresee non-target HBM screening to identify "emerging" pollutants of concern based on exposure and health risks to the general population. In addition, substitutes (of banned substances) will need to be tested in order to reliably assess their risks. It was highlighted by DG ENV representatives that from the chemicals unit point of view:

1. The highest priority for HBM from the point of view of Commission services is its potential use in risk assessment of mixture toxicity, as it is a unique instrument for assessment of the total burden of exposure of a population at a given time.

2. A second priority was seen in the field of REACH (substances of high and of less concern) where risk assessment is foreseen in the prioritisation and authorisation process.

\subsubsection{Validated analytical methods for biomarker determination}

Reliable and validated methods for sampling and analysis of selected biomarkers are a crucial element and selection criterion for the application of HBM. Chemical-analytical methods need to be specific and sensitive enough to detect environmental exposure and QA/QC systems need to be established to ensure sufficient reliability (Schindler et al., 2014; Esteban et al., this issue). As currently HBM methods are available for only a minor share of the 100,000 chemicals on the market, policy makers and scientist identified an urgent need to speed up the development or adjustment of methods in order to allow sufficiently fast analysis at reasonable prices.

\subsubsection{Monitoring protocols and quality assurance systems}

Study protocols and study design are a key parameter for the information and results that are generated with HBM and have considerable implications on budget needs (Becker et al., 2013). In addition ethical and data protection issues play an important role. As compatible study design is considered crucial for the generation of comparable results, whilst needs and capacities of Member States can be quite different, there is as fundamental need for a decision structure to set standards and elements to be contained. 


\subsubsection{Data management, data interpretation and data communica-} tion issues

From the European policy perspective it is essential to be able to perform evaluation and interpretation of data collected in Members States on a European scale. Information needs for policy making were reported to comprise European average and range, or proportion of population above a guidance or limit value, time and spatial trends, interregional variability and aspects of environmental justice. The European Commission proposal related to the establishment of an "Information Platform for chemical monitoring" considered compatible data storage systems on national level with virtual linkage and exchange procedures managed by EEA or JRC as important starting point towards an integrated data use. The integration of HBM data into the virtual European platform was considered a priority for the chemicals unit of the European Commission Directorate General for Environment in the light of the assessment of mixture toxicity.

Interpretation of HBM data requires a considerable amount of additional information to allow trace back to potential sources and to be able to estimate health risks using health based guidance values (Angerer et al., 2011; Bevan et al., 2012; Hays and Aylward, 2012).

Interpretability of HBM results also depends on sample size and recruitment patterns in terms of geographical and demographic stratification, with a population representative sample as ideal although not mandatory (see Kolossa-Gehring et al. (2011); Fiddicke et al., this issue). Experts globally agree that there is need to continue research into tools to assess the sources of exposure and in evaluation of toxicological and health impacts of different levels of exposure to environmental chemicals. Decisions also need to be taken concerning use of existing options for collaboration to further improve and increase cost-efficiency in terms of data management and interpretation.

Policy makers need clear information about potential risks on national, regional or local scale and about needs for action from the public health or environmental point of view, whereas individuals need to be informed about their personal risks. Given the particular alerting power of HBM, responsible communication is important and can be challenging in terms of balancing advantages and risks. In this context it is crucial to use similar benchmarks and to provide similar messages across Europe and to carefully balance benefits and risks (see Exley et al., this issue).

\subsubsection{Budgets, resources and responsibilities}

In times of financial constraints and low budgets there exist high hurdles to fund costly programmes even if considered relevant. Costs of HBM surveys were hence considered a key parameter for its potential use as policy tool. Shared funding solutions, prioritisation of stressors and risks, as well as optimised protocols, and effective use of existing resources for surveillance were highlighted as priorities and prerequisites for a continued use of HBM. In this context it was considered important to coordinate to the extent possible the guidance and protocols developed by national, European and international monitoring programmes/initiatives. Read-across of monitoring and research results from one country to another was suggested as another option to increase efficiency and reduce costs.

Expert discussions highlighted the challenge to find an appropriate funding body for HBM, given the fact that surveillance is observational in nature and is at the interface between research, and a considerable range of sectorial policies under responsibilities of various ministries on European, national, regional and local level. Responsibilities are distributed to Environment, Health and Consumers, Enterprise and Industry, Employment, Social Affairs and Equal Opportunities as well as Research and Innovation.

\subsection{A concept for a European infrastructure to ensure sustainable HBM}

In order to establish a European HBM programme that is comparable to national surveys in other industrialised countries, there is need for a sustainable structure and framework that will allow an expansion of the scope of the pilot, the identification of priority areas for use and a cost-efficient and targeted integration with other existing surveillance structures, data sources and data storing tools. To ensure consistency of Member State action overarching structures and responsibilities complementary to MS systems in place and could be established on European scale.

The concept as presented in Fig. 1 could constitute a structural framework allowing for an efficient and coordinated implementation and use of HBM taking into account best scientific and economic knowledge and being open to technical progress and methodological developments over time. Key elements are a European structure and a decision body for harmonisation, and coordination purposes, and elaboration of guidance. This comprises, in particular, the identification of priority substances and validated biomarkers, as well as methodologies to ensure comparable HBM results, to derive reference values and health based guidance values, to interpret and communicate HBM data, and decisions on study design, data storage and exchange, and review procedures. A cost-efficient integrated surveillance system and network at Member State level responsible for national surveys, and a European funding body to support technology development and ongoing research are further key elements.

The proposed framework is ambitious and demanding in terms of cooperation between parties involved, but examples from overseas show the feasibility of such a scheme. They furthermore demonstrate that such systems can be designed on a long-term perspective, with a considerable added value for policy-making. In addition, the framework is modular and can be established in a stepwise approach starting from an informal information exchange to develop into a legally based infrastructure.

Proposed core infrastructural pillars of the framework are a European HBM suggestion and coordination structure, a selection procedure for the identification and prioritisation of substances and method development linked to existing EU law and upcoming threat, and a HBM implementation and enforcement network embedded in Member States.

\subsubsection{EU HBM suggestion and coordination platform}

A key element of the proposed structure would be a platform designed to enable information exchange and decision making between competent authorities of the European Union, stakeholders and scientists. In particular, for prioritisation of substances and biomarker development, survey design and communication issues, and to ensure a systematic introduction of candidate substances for a risk and feasibility based selection and prioritisation procedure.

The platform should serve to collect requirements of policy makers and to prioritise potential candidates for European HBM studies. It could receive automatically all substances that are regulated to minimise use and exposure or are under discussion for further regulation, in a similar approach like in the United States or other States, where candidate substances are taken from the national registries of substances of concern.

In addition, the platform should be open to nomination of additional "ad hoc" candidates. Such nominations could be allowed for each citizen in the European Union including the scientific community, NGOs, public or industry - like in the United States (see box in the upper right corner of Fig. 1), or it could be restricted to Member State and European administration such as 


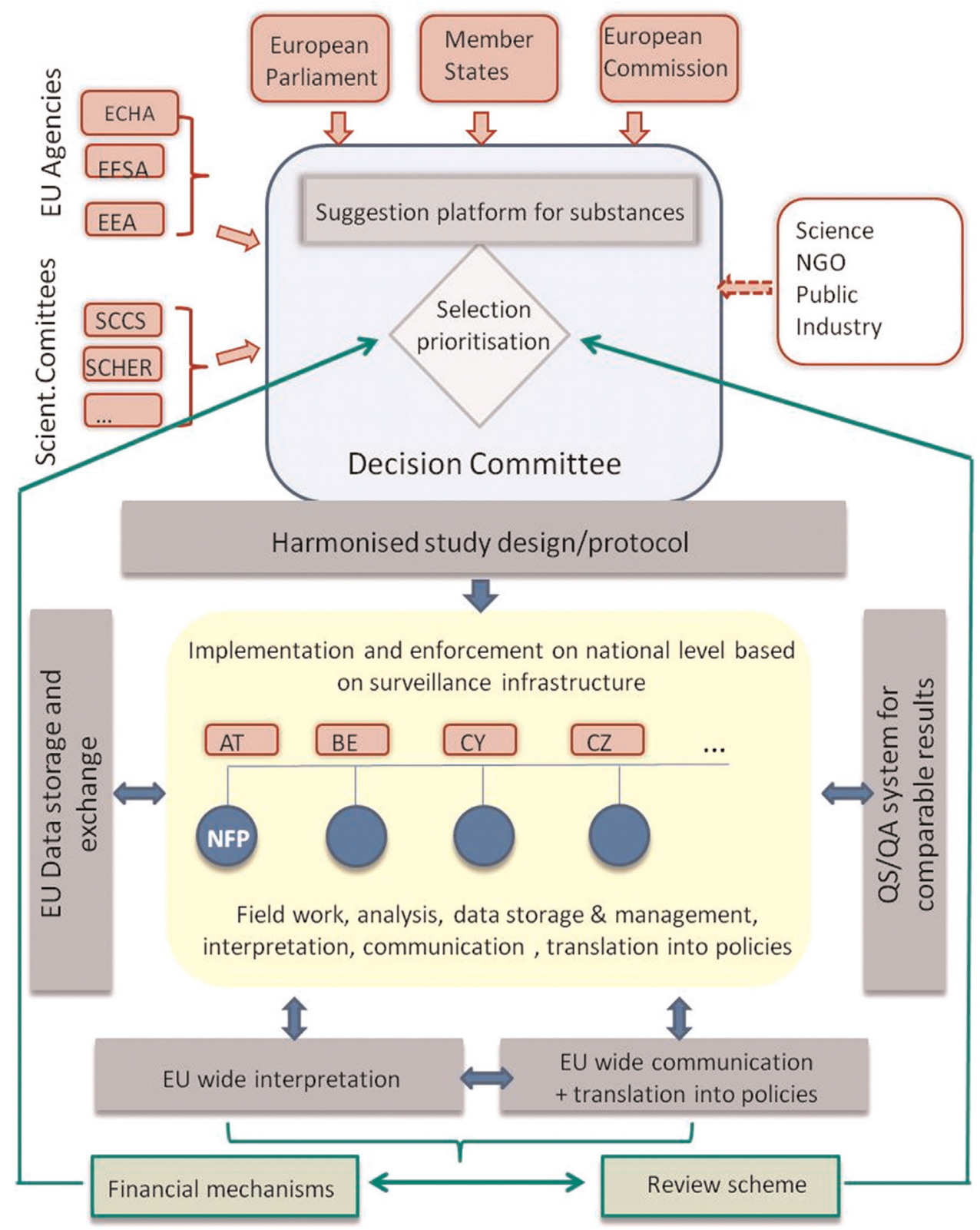

Fig. 1. Overview on the concept for a sustainable HBM in Europe.

European Parliament, European Commission, ECHA, EFSA, EEA, and related Scientific Committees.

Rights and procedures to bring forward candidate substances to the platform could follow procedures as established under the Stockholm Convention and the Aarhus Protocol on POPs or under REACH.

The European platform could be managed by one of the European Agencies (e.g. EEA, ECHA or JRC) and preferably would be financed by Commission Services. In this context it is important to notice that a corresponding role has been discussed as well for the "Information Platform for chemical Monitoring" planned by the European Commission as virtual data storage and exchange platform for environmental monitoring data.

\subsubsection{Decision scheme for prioritisation of substances for European} HBM studies

The purpose of the decision scheme is to provide best added value for invested efforts. Therefore the decision scheme could be based on a cost-benefit investigation related to the exposure knowledge gained. This aspect beyond many others speaks in favour of a close collaboration of environmental and public health authorities.

Following the example of national HBM programmes we recommend to base prioritisation on scientific and feasibility criteria such as health relevance and exposure risk to the general population, costs and benefits, political interest, adequate analytical methods, and available samples. The national benefit of analysing supplementary substances of national interest should be taken into account (Mørck et al., this issue) As decisions will be highly complex and will need to take into consideration latest scientific developments, decisions should be based on scientific investigations and consultations and on dossiers prepared by a scientific committee or advisory board composed of experts from academia, industry, and NGOs. This approach will allow the use of latest science that supports HBM programmes. It will be important in this phase to ensure close collaboration and feedback to European 
and national research authorities in order to promote research in areas where there are information gaps and needs.

Options to follow are the approaches used by ECHA and EFSA or the Stockholm Convention (dossiers), or the ones established by e.g. Germany, France or the USA (Casteleyn et al., this issue). The German HBM group and the joint initiative with the chemical industry could be used as an example for the design of a "fast but scientifically sound mechanism".

Given the financial and administrative implications of the selection procedure, final decisions on prioritisation would need to remain in the hands of competent authorities. Nominated Member State experts and Commission Services and representatives of the concerned agencies are suggested to form a Decision Committee.

A participatory approach involving stakeholder representatives, social scientist, politician, and civil society should be considered at this stage as well in order to ensure high acceptability (Keune et al., 2008).

The establishment of such a Decision Committee could be based on article 168, Para 2 Treaty on the Functioning of the European Union (TFEU). Also the inclusion of HBM in the $7^{\text {th }}$ European Environment Action Programme or in a revised Endocrine disrupting chemical (EDC) strategy would give sufficient legal background to allow DG Environment to take initiative in this respect. Examples that could be used as a model are e.g. the advisory groups CARACAL, CASC NANO, POPRC, or the Indoor Air working Group. In the long-term perspective it ideally might follow the examples of the Stockholm Convention and REACH. Another option would be the establishment of a European Research Infrastructure Consortium (ERIC).

\subsubsection{The HBM implementation and enforcement network (national and European level)}

The network shall consist of an EU guidance unit for protocol development, quality assurance, data management, data interpretation, communication, translation into policy and of surveillance infrastructures in the Member States with mutual data and knowledge exchange. Clear organisation from the national (health and/or environmental authorities) to the local level, as well as systematic involvement of the national contact person in European consultations and the EU expert network is considered a crucial element. The scientific expertise in each MS should be involved in protocol development e.g. through open consultation.

3.3.3.1. National surveillance infrastructures. The majority of Member States have established surveillance infrastructures linked to either health or environmental authorities. In the proposed concept we would recommend to fully rely on the established infrastructure. For a smooth information flow it will be crucial to organise the infrastructure from the national to the local level with clear responsibilities and information transfer, and to systematically ensure involvement of the contact persons in each Member State into European consultations and to ensure regular personal contacts within a European network following e.g. the example of the DEMOCOPHES "National Focal Point" (NFP).

3.3.3.2. The European HBM coordination platform. In order to ensure comparable monitoring data on a European scale, which is considered as key parameter for use of HBM as policy tool, there is a need for central coordinating tasks that help Member States in establishing their HBM programmes in a harmonised or compatible way. Such coordination tasks could include guidance and advice on protocol development, quality standards and quality assurance systems and data analysis and interpretation as well as on communication, and training or knowledge exchange. Based on the experience from the pilot phase the European coordination platform should support exchange and prepare guidance or recommendations in particular for the following aspects where harmonisation would be beneficiary:

- Development and adjustment of study design/protocol

- Establishment and maintenance of QA/QC system

- European data exchange and potential data storage

- Data analysis and reporting

- Communication, interpretation and translation into policy

The European coordination platform could be part of the selection platform and decision scheme and committee, or the composition, legal basis and the structure could follow a similar approach.

The European HBM coordination platform shall closely cooperate and continuously take up latest scientific knowledge that supports HBM programmes via feedback and input from the European and national research authorities and shall trigger further research via identification of needs. European study protocol unit: Comparable and harmonised study design is considered crucial for the generation of comparable results, whereas on the other hand needs and capacities of Member States can be quite different. For maximum synergies surveys will need to be integrated as far as possible with planned and ongoing national surveillance programmes, or international activities initiated e.g. by WHO for implementation of the Parma Declaration requirements (Egorov et al., 2013).

The European Unit could support the integration of all these aspects in the development of a guidance that ideally would be flexible to new demands in terms of study population, recruitment areas, matrices and substances. Modular approaches with minimum and more extended survey designs might be considered to facilitate participation of Member States and to be able to adapt to financial limitations and constraints. Key aspects that should be tackled and addressed in the guiding EU protocol are the following:

1. Best arrangement of sample size and distribution (e.g. representative regions)

2. Use of and integration with existing national programmes and data.

3. Maximum coordination with guidance and protocols developed by existing national, European and international monitoring programmes/initiatives.

European unit for coordination of $Q C / Q A$ : $Q C / Q A$ aspects are crucial to enable comparable HBM results, and hence need to be coordinated at European scale. Whilst other national HBM programme commonly built on central laboratories a more diversified approach needs to be taken in the European Union in order to meet Member State needs. This could be achieved by a Committee composed of core national laboratories that jointly select reference laboratories for substances that have been prioritised. This committee could integrate or build on the NORMAN network (http://www.nor man-network.net/) established in 2005 to support exchange and method development on emerging substances and the validation and harmonisation of analytical methods.

European unit for data interpretation, communication and translation of results: (DEMO)COPHES concluded that interpretation and communication of results is a most sensitive and critical part of a European wide approach and that the high speed and strong interaction of information flows within the European Union have major implications on communication. Conflicting messages need to be avoided. Against this background guidance and recommendations developed at European level is considered an important ongoing priority in communication and interpretation, as well as for the elaboration of health based guidance values. 
European unit for data storage and management: As harmonised standards for data management and biobanking are a prerequisite for comparable European wide interpretation and potential reanalysis, it is considered crucial for future European HBM to establish guidance on these aspects and to establish one central data repository, which can virtually or physically be linked to national data bases. Based on current experiences and due to privacy issues a central European database or biobank is not feasible. We therefore recommend restricting EU coordination efforts to guidance for data management, data analysis, sample preparation for storage and biobank management as well as to a central independent and neutral repository for European wide analysis of coded data, or to a virtual database linking to national repositories. In the light of existing activities, the establishment of a European database and information exchange platform in one of the European agencies (e.g. EEA, JRC), and a close collaboration with the health information system managed by the Directorate General for Health and Consumers is considered as a promising approach. A first step towards this approach is the suggested integration of the current pilot HBM database structure into the chemicals database currently being developed by JRC, as initiated in a meeting between (DEMO)COPHES experts and Directorate General for Environment in Brussels in July 2012.

3.3.3.3. Interactions between Member States and European Institutions. Besides the guidance and support function of the European infrastructures for Member States, it is considered crucial to establish a reverse information transfer from Member States to the European institutions. This transfer could comprise in particular the provision of national survey data for European data bases, or the exchange of nationally/regionally developed good practise in study design, interpretation and communication. Such a more individualised approach could be used as a starting point of an intensified cooperation or could constitute a light version of a harmonised framework.

3.3.3.4. Potential for synergies in fieldwork or method development. As Health examination (HES) and Health Information (HIS) Surveys are population based and are collecting questionnaire data or biological samples similar to HBM, there is an overlap to both approaches which can be used to reduce costs of recruiting and sampling as successfully shown on national level. Combination with HES might be particularly beneficiary as participation rates tend to be higher than with isolated HBM and biological samples are taken together with clinical investigation and information on health state.

As food is still an important source of exposure to a wide range of chemicals an integration of nutrition surveys with health examination or HBM as currently performed in NHANES and some national programme in Europe could be another option to use synergies, and is in line with the objectives set by the European Food Safety Authority (EFSA).

Finally we consider synergies in method development and study design to be available from close collaboration with activities in other regions of the world and with activities organised by WHO. National HBM surveys have been suggested by WHO Europe as the data source for several indicators.

\subsubsection{Review mechanisms and continuous improvement of the network}

In the light of a sustainable system that ideally is not spending more money than it saves in terms of public health benefits, it is essential to focus on priority risks and to include a constant review and optimisation mechanism, based on indicators of success and efficiency.
The review mechanisms shall aim to collect feedback of every HBM related action and to improve procedures continuously. This concerns in particular prioritisation procedures, the study design, field work performance, laboratory work, data management and interpretation, as well as communication. It shall include the establishment of removal/reduction criteria to target resources to the most important needs. Such criteria could comprise the existence of a better biomarker, a clear decrease in contamination over time or the detection of chemicals with higher risk.

The review mechanism should also cover the ongoing optimisation of sample size and distribution (e.g. representative regions), based on the requested information level. Furthermore it should investigate and assess any upcoming options to use and integrate with existing national programmes and data, as well as guidance and protocols developed by national, European and international monitoring programmes/initiatives.

An ongoing horizon scanning and exchange with academia/ research highlight any new technological and scientific development in terms of biomarker or method development. The review mechanism could be used also for translation of results into policy recommendations and can trigger revisions in this field.

\subsubsection{Funding mechanisms}

Costs of harmonised HBM survey are an essential parameter for its potential use as policy tool. Budgets that can be spent are limited and may vary depending on economic conditions. On the other hand HBM will only be of value if repeated in regular intervals to show trends over time. As a general rule it can be stated that budgetary aspects will play an important role as a selection criterion both for the prioritisation of substances as well as for the study design. As costs for recruitment, sampling and analyses differ considerably, available budget will impact on the type of substances that can be measured, the frequency of measurements and the number of samples that can be taken. In order to allow flexibility whilst ensuring maximum comparability European guidance will be needed.

An annual fixed budget would allow adjustments e.g. the number of analyses by subgroups in relation to the analytical costs and to agreements on appropriate intervals for repeated analysis to assess time trends. Ideally Member States and European Commission would agree on a fixed budget, that could be spent annually, and a flexible set up of the guidance on study design. This should allow reducing the number of samples or the number of investigated substances in single countries in case of severe economic difficulties without endangering the infrastructure and the data collection for retrospective analysis. In addition, the funding mechanism shall request best cost-quality relations and screen for best market offers for chemical analysis.

For optimised use of available funding schemes, co-financing concepts for different aspects of the surveys as well as an optimised combination of similar survey approaches (see use of synergies) would need to be established on bilateral or multilateral basis on national as well as on European level. The European coordination unit could establish recommendations or guidance in this field. Co-funding between health and environmental authorities and involving where relevant other ministries, NGO and industry could in principal be considered for all aspects of HBM survey from protocol development to communication and reporting. An initial suggestion based on feedback from Commission Services is the following:

1. DG RTD: improvement of biomarkers, investigation of real-life chemical mixtures, and investigations of the presence and significance of health effects, analytical method development.

2. DG Environment /DG Sanco coordination tasks in line with the subsidiarity principle. 
3. Member States field work, analysis, data management, interpretation and communication on national level.

For a sustainable funding scheme it will be important to provide proof about the cost-benefit of HBM for public health costs.

\subsection{Budgetary requirements for a sustainable HBM framework}

In the following a cost and resource calculation is provided for a European wide HBM framework as proposed. The calculation is based on estimates from DEMOCOPHES and national surveys, and relates to the proposed future HBM infrastructure, and hence to a full blown network. Figures are differentiated for the establishment of a European decision making and selection platform and for the national surveillance infrastructure and shall not be considered more than estimates. The two scenarios are based on minimum and maximum resource needs from the pilot phase and on experiences with coordination tasks from COPHES and ESBIO. They are associated in part with considerable uncertainty. However, due to the experiences made in the pilot phase, both scenarios are realistic and imaginable for an EU HBM framework, just depending on the importance and therefore on the dimension and awareness of the network.

\subsubsection{Costs for core European units}

Based on the assumption of a European Commission permanent official in medium salary range of EC salary Table ( $€ 8000$; range $€ 2769.95-16944.98)$ and human resources of a half time (6 person months per year) up to a full time person (12 person months per year), annual costs for a European suggestion platform for HBM substances can be expected to be in the range of $€ 50,000$ 100,000 per year (Table 6). It is assumed that the platform is established within the EC.

For the Decision Committee an expert group is assumed with different dimensions for the minimal and the maximal scenario. Depending on number of meetings and number of experts involved this figure is relatively sensitive and can influence final overall costs. As illustrated in Table 7 the costs would account to roughly $€ 90,000$ per year based on a Decision Committee of 10 experts and a meeting frequency of two meetings per year, whilst they would raise by a factor of eight to $€ 720,000$ with an Expert Committee of 40 experts and a meeting frequency of four meetings per year. In addition annual travel costs in the range of $€$ $12,000(40 \times € 300)-96,000(320 \times € 300)$ are to be considered based on an average of $€ 300$ per travel day per person.

Based on the experiences of COPHES a European implementation unit is estimated to entail annual budgetary needs of $€$ 300,000-600,000 for coordination and further development of guidance work on study design, chemical analysis, communication and data management as illustrated in Table 8. The figure does not comprise the costs for development of new biomarkers or analytical methods.

This means that in the minimum scenario $€ 400,000$ and in the maximum scenario annual expenses of roughly $€ 1.4$ million are to be expected at European level. In the case of biobanking, additional costs, amounting approximately to 7,000,000 € per year, have to be considered based on the experience of the German Environment Specimen Bank.

\subsubsection{Budgetary requirements at national level}

Based on one measurement round each year comparable to the DEMOCOPHES approach, budgetary needs between $€ 120,000$ and 450,000 per year can be assumed as a best estimate at country level (Table 9).

In this context recruitment and sampling as well as sample handling and chemical analysis constitute the major determinants for costs, representing more than $50 \%$ of the overall estimated budgetary needs. For chemical analysis this share can even further increase considerably depending on the type of substances analysed.

With 28 Member states participating the overall costs would hence range from €3.8 Million (minimum scenario) to €14.1 Million (maximum scenario) annually.

\subsubsection{Costs of programmes established in USA and Canada}

The costs of a comparable HBM approach in the United States of America (NHANES ${ }^{1}$ ), funded by the US Congress, sum up to approximately 5 Million US Dollar per year. The NHANES approach includes 10,000 samples in 30 US states in a two year cycle. The Canadian Health Measures Survey $\left(\mathrm{CHMS}^{2}\right)$ calculated an overall sum of 35 Million Canadian Dollar for a 5 years approach, or roughly 7 Million Dollar per year. A comparison with an estimated annual average budget for the European Union for EU coordination and capacity in 28 Member States of €9 Million (range €3.8-14.1) shows that the calculation does not underestimate costs and that cost reduction compared to the pilot phase shall be expected by synergy of scale.

\subsubsection{Cost-benefits assessment for Europeanwide HBM}

In the past years, discussions on the benefits of HBM have been taken place in nearly every European Member State as well as at a European level. It is obvious that HBM is an excellent tool to assess people's health in an integrated way but is on the other hand also linked to high economic efforts. Not always an immediate benefit for policy makers is obvious and available, as results need to be set in relation to other available data or need to be considered in a long term perspective. An EU HBM Framework would realise this in the most efficient way. Data would be comparable within the EU and recurring data collections would allow seeing time trends and would allow evaluating the effectiveness of policy decisions to reduce or eliminate certain compounds in the environment. Limit values for European citizens could be established or maintained and exposure pathways could be identified in a uniform way. As Paustenbach and Galbraith (2006) stated "Biomonitoring can also reduce the uncertainty inherent within traditional exposure and risk assessments." A total of 14 Mio $€$ per year for the maximal scenario means less than 3 Cent per EU citizen per year.

\subsection{Options for integration of HBM into the European regulatory framework}

The example of occupational health legislation, or of the Stockholm Convention on POPs or of national legislation in e.g. Flanders and Slovenia illustrate how integration of HBM or monitoring in the regulatory framework promotes and ensures data generation. A mandatory data collection scheme is also considered a prerequisite to ensure the allocation of the necessary funding

Table 6

Suggestion platform for substances.

\begin{tabular}{|c|c|c|c|c|c|c|c|}
\hline & Financing by whom? & estimated $\mathrm{PM}^{\mathrm{a}}$ p.a. min & estimated PM p.a. max & costs in $€$ per PM & costs in $€ \min$ & costs in $€ \max$ & Sensitivity \\
\hline Electronic Platform & EC & 6 & 12 & 8000 & 48,000 & 96,000 & low \\
\hline
\end{tabular}

\footnotetext{
${ }^{\mathrm{a}} \mathrm{PM}=$ person month.
} 
Table 7

Decision committee assuming expert group.

\begin{tabular}{|c|c|c|c|c|c|c|c|}
\hline & Financing by whom? & $\begin{array}{l}\text { estimated PD p.a. } \\
\min ^{a}\end{array}$ & $\begin{array}{l}\text { estimated PD p.a. } \\
\max ^{\mathrm{b}}\end{array}$ & $\begin{array}{l}\text { average daily rate per expert } \\
{[€]}\end{array}$ & costs in $€ \min$ & costs in $€ \max$ & Sensitivity \\
\hline Decision committee & EC countries/EC & 100 & 800 & 900 & 90,000 & 720,000 & medium \\
\hline Travel costs & EC countries/EC & & & & 12,000 & 96,000 & low \\
\hline
\end{tabular}

a (10 experts, 2 annual two-day meetings, 3 days preparation each $=10 \times 10 \mathrm{PDs}$ ).

b (40 experts, 4 annual two-day meetings, 3 days preparation each $=40 \times 20$ PDs).

and to maintain skilled resources and appropriate capacities. For this reason it was considered as crucial in recent expert discussion to integrate HBM in key legal documents, thematic strategies, or action programmes in the policy fields such as Chemicals Legislation, Plant Protection Products (PPP), Biocides, Endocrine disruptors (EDC Strategy), or mercury (global mercury strategy) or the 7th Environment Action Programme. In this context a shared or joint responsibility between involved DGs, Agencies and Member States was considered important. Given the multi-responsibility of involved authorities and the need to integrate stakeholders and science, there is broad agreement about a framework that determines how to apply and where to integrate the different elements.

\subsubsection{European or International Policies suitable for integration of HBM}

By now only the Stockholm Convention on persistent Organic Pollutants, the Aarhus Protocol, and the European Regulation on Persistent Organic Pollutants (EC) no. 850/2004 as well as the Directive 98/24/EC “Chemical Agents Directive as supplemented by Directives 2000/39/EC and 2006/15/EC for protection of workers at workplace are explicitly requesting HBM.

In addition, there is a large number of other legislation, regulating emissions, production or use of substances or aiming at minimised exposures, which does not mention the use of HBM as alert or surveillance instrument, but relate to substances or product groups which are suspected to potentially cause environmental and health risks or are focussing on health prevention in general without a particular focus on environmental determinants. This legislation and these policy strategies have the potential to incorporate recommendation for the use of HBM, as they relate to aspects where association between environment and health is considered. Major examples of such substance/source oriented legislation or policies are the following:

1. The Reach regulation (EC) no. $1907 / 2006$

2. The Community strategy for endocrine disruptors

3. The Food Contact Materials Regulation no. (EC) 1935/2004 and the Regulation on Food Additives no. (EC) 1333/2008

4. The Toy Safety Directive 2009/48/EC

5. Regulation (EC) no. $1223 / 2009$ on cosmetic products

6. The Community Strategy Concerning Mercury as reviewed COM/2010/0723 final

7. The Water Framework Directive (WFD) 2000/60/EC together with the Decision on Environmental Quality Standards for
Surface waters 2008/105/EC and the Groundwater Directive 2006/118/EC

8. The Air Quality Directive 2008/50/EC

9. Biocidal Products Regulation no. (EC) 528/2012

10. Plant Protection Products Regulation (PPP) (EC) no. 1107/2009

11. Environment Action Programmes

12. Public Health Programmes

Finally it is worth mentioning recent priorities on assessment of mixture toxicity which might be associated to HBM. The draft communication from the Commission to the Council prepared suggests several options in order to improve risk assessment. These include:

1. Ad-hoc working group for coordination of data collection and integrated assessment

2. Review of monitoring data currently collected in research and under EU legislation

3. More coherent generation, collection, storage and use of chemical monitoring data

\subsubsection{Added value that harmonised HBM could provide to EU policies}

European wide HBM can contribute both to European environment and public health policies. In environmental policies harmonised HBM can in particular respond to key objectives as illustrated in Fig. 2.

In public health policies the responsibility of the European Commission is focussing on risk assessment in food and feed safety, legislation on veterinary medicinal products, plant protection products (pesticides), biocides and consumer products.

HBM can contribute to the objectives of the current European Public Health Programme (Health for Growth) due to the fact that it can contribute to a proper risk assessment and safety evaluation of all substance groups regulated in the food and feed legislation and it can close the gap between environmental data and health outcomes, and provide the necessary data for potential environmental determinants of major chronic diseases, and can support and follow up preventive actions. Furthermore it can contribute to monitoring, and early warning for cross-border health threats, in particular regarding chemical incidents and environmental/anthropogenic threats, and in combination with toxicological assessments it can contribute to health information and knowledge to contribute to evidence-based decision making.

Table 8

EU implementation unit.

\begin{tabular}{|c|c|c|c|c|c|c|c|}
\hline & & $\begin{array}{l}\text { estimated PM p.a. } \\
\text { min }\end{array}$ & $\begin{array}{l}\text { estimated PM p.a. } \\
\max \end{array}$ & $\begin{array}{l}\text { average PM } \\
\text { salary }\end{array}$ & $\begin{array}{l}\text { Total costs in } € \\
\text { min }\end{array}$ & $\begin{array}{l}\text { Total costs in } € \\
\max \end{array}$ & Sensitivity \\
\hline $\begin{array}{l}\text { EU study protocol } \\
\text { unit }\end{array}$ & EC countries/EC & 60 & 120 & 5000 & 300,000 & 600,000 & $\begin{array}{l}\text { high depending on dimen- } \\
\text { sion of network }\end{array}$ \\
\hline
\end{tabular}


Table 9

National HBM implementation and enforcement network (per country).

\begin{tabular}{|c|c|c|c|c|c|c|}
\hline \multirow[t]{2}{*}{ Tasks } & \multicolumn{2}{|c|}{ Estimated PM p.a. } & \multicolumn{4}{|l|}{ Costs in $€$} \\
\hline & $\min$ & $\max$ & $\begin{array}{l}\text { Average PM } \\
\text { salary }\end{array}$ & Costs in $€ \min$ & Costs in $€ \max$ & Sensitivity \\
\hline operational framework & 6 & 18 & 5000 & 30,000 & 90,000 & medium \\
\hline $\begin{array}{l}\text { sampling and recruitment and sample } \\
\text { collection }\end{array}$ & 6 & 24 & 5000 & 30,000 & 120,000 & $\begin{array}{l}\text { high depending on number of samples and } \\
\text { study design }\end{array}$ \\
\hline sample handling, chemical analysis & 6 & 24 & 5000 & 30,000 & 120,000 & high depending on chemicals measured \\
\hline data analysis and integrated interpretation & 3 & 12 & 5000 & 15,000 & 60,000 & high depending on data volume \\
\hline \multirow{2}{*}{ communication and dissemination } & 3 & 12 & 5000 & 15,000 & 60,000 & low \\
\hline & & & SUM & 120,000 & 450,000 & \\
\hline
\end{tabular}

3.6. Major policy recommendations from the stakeholder consultations

The stakeholder consultations namely the conference on the proposed framework in Paris 2012 concluded that it is time to intensify collaboration at European and international level and to set up the necessary means for harmonisation of practices, to optimise the investments made and to increase efficiency. The conference recommended establishing the framework to enable a European view to interpret and to communicate HBM data to translate results into management measures, and to increasingly use HBM for investigation of exposure to mixtures, and for the risk assessment of REACH substances of less concern. It recommended establishing an efficient data exchange system integrating existing HBM data to solve related data protection and ethical aspects and to establish a European "host" agency for analytical quality assurance and data storage, or even for European wide data analysis. EC and Member States should take steps to strengthen collaboration with HES/HIS/Nutrition for increased monitoring efficiency and Member States should consider the elaboration of a European Research Infrastructure Consortium (ERIC) proposal to establish the legal basis for an exchange platform.

Information exchange, guidance on optimum approaches and priorities, and facilitation of tailor-made Member State action (adherent to comparable standards) could be a key priority for the European Commission. Options for collaboration and coordination with European and international agencies dealing with aspects related to surveillance or chemicals such as ECDC, SAICM, WHO should be considered thoroughly. In the light of thousands of chemicals on the market and coming to the market in short intervals the prioritisation of substances could be one of the highest priorities for a European platform, and in the light of lack of knowledge about health impacts, the development of health based threshold values should be prioritised and Member States should be assisted in communication of results.

Sharing of efforts between involved experts in particular for technology and method development and use of read-across to speed up decision making and method development, and use of environmental surveillance in substance prioritisation and setting up of survey design should be promoted as well as read-across from occupational exposure to general population, by starting method development for general population when occupational exposure observed.

The experts recommended to focus on the integration of HBM in REACH authorisation procedures, and on the inclusion of new substances/exposure sources (extent to concept of "civilisation exposures") and to take initiatives to develop intelligent solutions facilitating more efficient use of HBM on European scale (better use of existing databases), pooled data, novel sampling strategies, representative regions concept, method development, etc.). It was recommended to foster multi-disciplinary collaboration, cooperation and information exchange across all professions involved (in particular epidemiologists, toxicologists, HBM experts) and to support coupling of HBM, HES, HIS, environmental measurements, cohort studies and research.

\begin{tabular}{l|l|} 
REACH & $\begin{array}{l}\text { 1. substance evaluation } \\
\text { 2. restriction and authorisation; } \\
\text { 3. implementation control }\end{array}$ \\
\hline
\end{tabular}

\begin{tabular}{|c|c|}
\hline \multirow[t]{5}{*}{ 7EAP } & $\begin{array}{l}\text { 1. close the gap between environmental data \& health, provide data for better protection } \\
\text { of human health and social well-being }\end{array}$ \\
\hline & 2. contribute to a proper assessment and consideration of potential impacts on health \\
\hline & 3. contribute to knowledge about exposure related to new \& emerging challenges \\
\hline & 4. provide reliable, up-to-date data on internal exposure and potential impacts on health. \\
\hline & 5. contribute to a Europeanwide information system, improved surveillance regimes \\
\hline
\end{tabular}

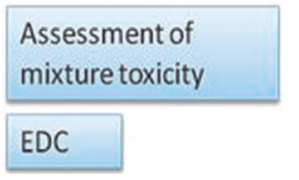

Comparable data for risk assessment

Fig. 2. Environmental Policy objectives that can be supported by HBM. 


\section{Conclusions}

Improved use of biomonitoring data, including better access for secondary use and better comparability is an important objective in European environmental and health policies. Comparable monitoring data on European scale are considered a key parameter for effective use of HBM as policy tool.

In order to keep the advantages of the expertise in harmonised HBM, acquired in the European pilot study by COPHES and DEMOCOPHES, there is need to establish a European framework that will allow an efficient and targeted use of the tool in future. The pilot projects concluded that there is a clear need and benefit of a European framework to allow sustainable HBM in Europe.

In Europe responsibility for HBM is distributed to 28 Member States, but approaches comparable to those established e.g. in the USA and Canada are principally applicable as well. The proposed concept with the two overarching infrastructural pillars:

1) EU HBM suggestion and coordination platform for prioritisation and guidance, and

2) HBM implementation and enforcement network,

presents a fully elaborated structure considered sustainable. It is ambitious in terms of benefits and willingness to collaborate, but it can be realised in a stepwise approach. Starting point can be a data storage and exchange system and a systematic information exchange (platform) between involved authorities, developing into an open-ended decision and management structure over time.

Key tasks of the overarching structure would be guidance on study protocols, data interpretation, communication and translation of results, data storage and management, funding and review schemes. The virtual European platform for chemical monitoring developed by JRC could serve as an appropriate platform also for data storage HBM.

\section{Funding sources}

COPHES was coordinated by BiPRO GmbH, Germany, with the University of Leuven, Belgium and was funded by DG Research in the Seventh Framework Programme (FP7/2007-2013).

DEMOCOPHES (LIFE09 ENV/BE/000410) was coordinated by the Federal Public Service Health, Food Chain Safety and Environment, Belgium and was jointly financed by the European Commission LIFE + programme (50\%) and national institutions in each participating country.

For information on both projects as well as on the national cofunding institutions: see http://www.eu-hbm.info/.

\section{Acknowledgements}

We would like to thank in particular the work package leaders of COPHES that contributed to the development of the concept and the experts from Commission Services, Centers for Disease Control and Prevention (CDC), Health Canada, WHO and Member State authorities that contributed with presentations and discussion to the further refinement and development. We would also like to thank all project partners of COPHES and DEMOCOPHES and other research groups in the European Member States, other European countries and countries worldwide that supported the project with information and experience.

\footnotetext{
${ }^{1}$ http://www.cdc.gov/nchs/nhanes.htm

2 http://www23.statcan.gc.ca/imdb/p2SV.pl?

Function $=$ getSurvey $\&$ SDDS $=5071 \&$ lang $=e n \& d b=i m d b \& a d m=8 \& d i s=2$
}

\section{References}

Angerer, J., 2012. Strengths and limitations of HBM - yes we can!. Int. J. Hyg. Environ. Health 215, 96-97.

Angerer, J., Aylward, L.L., Hays, S.M., Heinzow, B., Wilhelm, M., 2011. Human biomonitoring assessment values: approaches and data requirements. Int. J. Hyg. Environ. Health 214, 348-360.

Becker, K., Seiwert, M., Casteleyn, L., Joas, R., Joas, A., Biot, P., Aerts, D., Castaño, A., Esteban, M., Angerer, Jn, Koch, H.M., Schoeters, G., Den Hond, E., Sepai, O., Exley, K., Knudsen, L.E., Horvat, M., Bloemen, L., Kolossa-Gehring, M., 2013. A systematic approach for designing a HBM pilot study for Europe. Int. J. Hyg. Environ. Health 217, 312-322.

Bergkvist, C., Lignell, S., Sand, S., Aune, M., Persson, M., Håkansson, H., Berglund, M., 2010. A probabilistic approach for estimating infant exposure to environmental pollutants in human breast milk. J. Environ. Monit. 12 (5), 1029-1036.

Bevan, R., Angerer, J., Cocker, J., Jones, K., Koch, H.M., Sepai, O., Schoeters, G., Smolders, R., Levy, L., 2012. Framework for the development and application of environmental biological monitoring guidance values. Regul. Toxicol. Pharmacol. 63, 453-460.

Bevan, R., Jones, K., Cocker, J., Assem, F.L., Levy, L.S., 2013. Reference ranges for key biomarkers of chemical exposure within the UK population. Int. J. Hyg. Environ. Health 216, 170-174.

Calafat, A.M., 2012. The U.S. National Health and Nutrition Examination Survey and human exposure to environmental chemicals. Int. J. Hyg. Environ. Health 215, 99-101.

Casas, M., Chevrier, C., Hond, E.D., Fernandez, M.F., Pierik, F., Philippat, C., Slama, R., Toft, G., Vandentorren, S., Wilhelm, M., Vrijheid, M., 2013. Exposure to brominated flame retardants, perfluorinated compounds, phthalates and phenols in European birth cohorts: ENRIECO evaluation, first human biomonitoring results, and recommendations. Int. J. Hyg. Environ. Health 216, 230-242.

Casteleyn L., Dumez B., Becker K., Kolossa-Gehring M., Den Hond E., Schoeters G., Castaño A., Koch H.M., Angerer J., Esteban M., Exley K., Sepai O., Bloemen L., Horvat M., Knudsen L.E., Joas A., Joas R., Biot P., Koppen G., Dewolf M-C., Katsonouri A., Hadjipanayis A., Cerna M., Krskova A., Schwedler G., Fiddicke U., Nielsen J.K.S., Jensen J.F., Rudnai P., Kozepesy S., Mulcahy M., Mannion R., Gutleb A.C., Fischer M.E., Ligocka D., Jakubowski M., Reis M.F., Namorado S., Lupsa I-R., Gurzau A.E., Halzlova K., Jajcaj M., Mazej D., Tratnik Snoj J., Posada M., Lopez E., Berglund M., Larsson K., Lehmann A., Crettaz P., Aerts D., 2014. A pilot study on the feasibility of European harmonized human biomonitoring: challenges and opportunities, Submitted to be included in this "Special issue".

Centers for Disease Control and Prevention (CDC), 2010. National Report on Human Exposure to Environmental Chemicals. Atlanta: CDC

Cerna, M., Krskova, A., Cejchanova, M., Spevackova, V., 2012. Human biomonitoring in the Czech Republic: an overview. Int. J. Hyg. Environ. Health 215, 109-119.

Commission of the European Communities, 2007. Mid Term Review of the European Environment and Health Action Plan 2004-2010, Communication from the Commission to the Council, the European Parliament and the European Economic and Social Committee, Brussels, 11.6.2007, COM (2007) 314 final.

Conrad, A., Schulz, C., Seiwert, M., Becker, K., Ullrich, D., Kolossa-Gehring, M., 2010. German environmental survey IV: children's exposure to environmental tobacco smoke. Toxicol. Lett. 192, 79-83.

De Felip, E., Bianchi, F., Bove, C., Cori, L., D’Argenzio, A., D’Orsi, G., Fusco, M., Miniero, R., Ortolani, R., Palombino, R., Parlato, A., Pelliccia, M.G., Peluso, F., Piscopo, G., Pizzuti, R., Porpora, M.G., Protano, D., Senofonte, O., Spena, S.R., Simonetti, A., di Domenico, A., 2014. Priority persistent contaminants in people dwelling in critical areas of Campania Region, Italy (SEBIOREC biomonitoring study). Sci. Total Environ. 487, 420-435.

Egorov, A.I., Dalbokova, D., Krzyzanowski, M., 2013. Biomonitoring-based environmental public health indicators. Methods Mol. Biol. 930, 275-293.

Esteban, M., Schindler, B.K., Koch, H.M., Jiménez-Guerrero, J.A., Koch, H.M., Angerer, J., Rivas, T.C., Navarro, C., Schoeters, G., Den Hond, E., Bloemen, L.,Rosado, M., Gómez, S., Casteleyn, L., Kolossa-Gehring, M., Becker, K., Schoeters, G., Den Hond, E., Bloemen, L., Sepai, O., Exley, K., Knudsen, L.E., Horvat, M., Joas, A., Joas, R., Aerts, D., Biot, P., Borošová, D., Davidson, F., Dumitrascu, I., Fischer, M.E., Grander, M., Janasik, B., Jones, K., Kašparová, L., Larssen, T., Naray, M., Nielsen, F., Hohenblum, P., Pinto, R., Pirard, C., Plateel, G., Tratnik, J.S., Wittsiepe, J.et al., EQUAS Reference Laboratories, Castaño A., 2014. Mercury analysis in hair: Comparability and quality assessment within the transnational COPHES/DEMOCOPHES project. Submitted to be included in this "Special issue".

Fiddicke, U., Becker. K., Schwedler, G., Seiwert, M., Joas, R., Joas, A., Biot, P., Aerts, D., Casteleyn, L., Dumez, B., Castaño, A., Esteban, M., Angerer, J., Koch, H.M., Schoeters, G., Den Hond, E., Sepai, O., Exley, K., Knudsen, L.E., Horvat, M., Bloemen, L., Katsonouri, A., Hadjipanayis, A., Cerna, M., Krsková, A., Fangel Jensen, J., Nielsen, J.K.S, Rudnai, P., Közepésy, S., Gutleb, A.C.o, Fischer M.E., Ligocka, D., Kamińska, J., Reis, F.M., Namorado, S., Lupsa I.R., Gurzau, A.E., Halzlova, K., Mazej, D., Snoj Tratnik, J., Rivas, T.C., Gómez S., Berglund, M., Larsson, K., Lehmann, A., Crettaz, P., Dewolf, M.C., Burns, D., Kellegher, A., KolossaGehring, M., 2014. Lessons learnt on recruitment and fieldwork from a pilot European human biomonitoring survey. Submitted to be included in this "Special issue".

Frederiksen, H., Jensen, T.K., Jorgensen, N., Boye Kyhl, H., Husby, S., Skakkebaek, N. E., Main, K.M., Juul, A., Andersson, A.M., 2014. Human urinary excretion of nonpersistent environmental chemicals: an overview of Danish data collected between 2006-2012. Reproduction 147 (4), 555-565. 
Fréry, N., Vandentorren, S., Etchevers, A., Fillol, C., 2012. Highlights of recent studies and future plans for the French human biomonitoring (HBM) programme. Int. J. Hyg. Environ. Health 215, 127-132.

Haines, D.A., Murray, J., 2012. Human biomonitoring of environmental chemicals early results of the 2007-2009 Canadian Health Measures Survey for males and females. Int. J. Hyg. Environ. Health 215, 133-137.

Hays, S.M., Aylward, L.L., 2012. Interpreting human biomonitoring data in a public health risk context using Biomonitoring Equivalents. Int. J. Hyg. Environ. Health 215, 145-148.

Hebels, D.G., Georgiadis, P., Keun, H.C., Athersuch, T.J., Vineis, P., Vermeulen, R., Portengen, L., Bergdahl, I.A., Hallmans, G., Palli, D., Bendinelli, B., Krogh, V., Tumino, R., Sacerdote, C., Panico, S., Kleinjans, J.C., de Kok, T.M., Smith, M.T. Kyrtopoulos, S.A., EnviroGenomarkers Project, C., 2013. Performance in omics analyses of blood samples in long-term storage: opportunities for the exploitation of existing biobanks in environmental health research. Environ. Health Perspect. 121, 480-487.

Hohenblum, P., 2012. Pollution gets personal! A first population-based human biomonitoring study in Austria. Int. J. Hyg. Environ. Health 215 (2), 176-179.

Jakubowski, M., Trzcinka-Ochocka, M., 2005. Biological monitoring of exposure: trends and key developments. J. Occup. Health 47, 22-48.

Joas, R., Casteleyn, L., Biot, P., Kolossa-Gehring, M., Castano, A., Angerer, J., Schoeters, G., Sepai, O., Knudsen, L.E., Joas, A., Horvat, M., Bloemen, L., 2012. Harmonised human biomonitoring in Europe: activities towards an EU HBM framework. Int J. Hyg. Environ. Health 215, 172-175.

Joas, A., Polcher, A., Casteleyn, L., Biot, P., Aerts, D., Kolossa-Gehring, M., Castano, A., Angerer, J., Schoeters, G., Sepai, O., Knudsen, L.E., Horvat, M., Bloemen, I, Joas, R., 2012. Harmonized Human Biomonitoring in Europe: Activities Towards an EU HBM Framework. Issues in Toxicology No. 9: Biomarkers and Human Biomonitoring, vol. 1. Ongoing Programs and Exposures, The Royal Society of Chemistry, Cambridge, UK, ISBN: 978-1-84973-241-3.

Keune, H., Morrens, B., Loots, I., 2008. Risk communication and human biomonitoring: which practical lessons from the Belgian experience are of use for the EU perspective? Environ. Health 7 (Suppl 1), S11.

Knudsen, L.E., Merlo, D.F. (Eds.), 2012. Issues in Toxicology No. 9: Biomarkers and Human Biomonitoring, vol. 1. Ongoing Programs and Exposures, The Royal Society of Chemistry, Cambridge, UK, ISBN: 978-1-84973-241-3.

Kolossa-Gehring, M., 2012. Human biomonitoring: political benefits - scientific challenges. Int. J. Hyg. Environ. Health 215, 247-252.

Kolossa-Gehring M;, Becker K., Fiddicke U., Schulz C., Conrad A., Schröter-Kermani C., Seiwert M., 2011. Biomonitoring as a key tool in environmental health, the German approach. 〈http://www.milieu-en-gezondheid.be/resultaten/ 2007-2011/studiedag 21-12-2011/abstract MK.pdf (accessed April 8th).

Kolossa-Gehring, M., Becker, K., Conrad, A., Schroter-Kermani, C., Schulz, C., Seiwert, M., 2012. Environmental surveys, specimen bank and health related environmental monitoring in Germany. Int. J. Hyg. Environ. Health 215, 120-126.

Kyrtopoulos, S.A., 2013. Making sense of OMICS data in population-based environmental health studies. Environ. Mol. Mutagen. 54, 468-479.

Leventakou, V., Roumeliotaki, T., Martinez, D., Barros, H., Brantsaeter, A.L., Casas, M., Charles, M.A., Cordier, S., Eggesbo, M., van Eijsden, M., Forastiere, F., Gehring, U., Govarts, E., Halldorsson, T.I., Hanke, W., Haugen, M., Heppe, D.H., Heude, B., Inskip, H.M., Jaddoe, V.W., Jansen, M., Kelleher, C., Meltzer, H.M., Merletti, F. Molto-Puigmarti, C., Mommers, M., Murcia, M., Oliveira, A., Olsen, S.F., Pele, F., Polanska, K., Porta, D., Richiardi, L., Robinson, S.M., Stigum, H., Strom, M., Sunyer, J., Thijs, C., Viljoen, K., Vrijkotte, T.G., Wijga, A.H., Kogevinas, M., Vrijheid, M., Chatzi, L., 2014. Fish intake during pregnancy, fetal growth, and gestational length in 19 European birth cohort studies. Am. J. Clin. Nutr. 99, 506-516.

Manno, M., Viau, C., in collaboration, w, Cocker, J., Colosio, C., Lowry, L., Mutti, A. Nordberg, M., Wang, S., 2010. Biomonitoring for occupational health risk assessment (BOHRA). Toxicol. Lett. 192, 3-16.

Merlo, D.F., Agramunt, S., Anna, L., Besselink, H., Botsivali, M., Brady, N.J., Ceppi, M., Chatzi, L., Chen, B., Decordier, I., Farmer, P.B., Fleming, S., Fontana, V., Forsti, A., Fthenou, E., Gallo, F., Georgiadis, P., Gmuender, H., Godschalk, R.W., Granum, B., Hardie, L.J., Hemminki, K., Hochstenbach, K., Knudsen, L.E., Kogevinas, M., Kovacs, K., Kyrtopoulos, S.A., Lovik, M., Nielsen, J.K., Nygaard, U.C., Pedersen, M., Rydberg, P., Schoket, B., Segerback, D., Singh, R., Sunyer, J., Tornqvist, M., van Loveren, H., van Schooten, F.J., Vande Loock, K., von Stedingk, H., Wright, J., Kleinjans, J.C., Kirsch-Volders, M., van Delft, J.H., NewGeneris, C., 2014. Micronuclei in cord blood lymphocytes and associations with biomarkers of exposure to carcinogens and hormonally active factors, gene polymorphisms, and gene expression: the NewGeneris cohort. Environ. Health Perspect. 122, 193-200.
Mørck, T.A., Nielsen, F., Nielsen, J.K., Siersma, V.D., Grandjean, P., Knudsen, L.E. 2014a. PFAS concentrations in plasma samples from Danish school children and their mothers. Chemosphere.

Mørck T.A., Nielsen F., Nielsen J.K., Jensen J.F., Hansen P.W., Hansen A.K., Christoffersen L.N., Siersma V.D., Larsen I.H., Hohlmann L.K., Skaanild M.T., Frederiksen F., Biot P., Casteleyn L., Kolossa-Gehring M., Schwedler G., Den Hond E., Schoeters G., Castaño A., Esteban M., Angerer J., Koch H.M., Bloemen L., Exley K. Sepai O., Joas A., Joas R., Aerts D., Fiddicke U., Lopez A., Cañas A., Knudsen L.E., 2014b. The Danish contribution to the European DEMOCOPHES project: a description of cadmium, cotinine and mercury levels in Danish mother-child pairs and the perspectives of supplementary sampling and measurements (same issue).

Papadopoulou, E., Caspersen, I.H., Kvalem, H.E., Knutsen, H.K., Duarte-Salles, T., Alexander, J., Meltzer, H.M., Kogevinas, M., Brantsaeter, A.L., Haugen, M., 2013. Maternal dietary intake of dioxins and polychlorinated biphenyls and birth size in the Norwegian Mother and Child Cohort Study (MoBa). Environ. Int. 60, 209-216.

Paustenbach, D., Galbraith, D., 2006. Biomonitoring and biomarkers: exposure assessment will never be the same. Environ. Health Perspect. 114 (8), 1143-1149.

Pedersen, M., Schoket, B., Godschalk, R.W., Wright, J., von Stedingk, H., Tornqvist, M., Sunyer, J., Nielsen, J.K., Merlo, D.F., Mendez, M.A., Meltzer, H.M., Lukacs, V., Landstrom, A., Kyrtopoulos, S.A., Kovacs, K., Knudsen, L.E., Haugen, M., Hardie, L. J., Gutzkow, K.B., Fleming, S., Fthenou, E., Farmer, P.B., Espinosa, A., Chatzi, L., Brunborg, G., Brady, N.J., Botsivali, M., Arab, K., Anna, L., Alexander, J., Agramunt S., Kleinjans, J.C., Segerback, D., Kogevinas, M., 2013. Bulky dna adducts in cord blood, maternal fruit-and-vegetable consumption, and birth weight in a European mother-child study (NewGeneris). Environ. Health Perspect. 121, 1200-1206.

Perharic, L., Vracko, P., 2012. Development of national human biomonitoring programme in Slovenia. Int. J. Hyg. Environ. Health 215, 180-184.

Reis, M.F., Tedim, J., Aguiar, P., Miguel, J.P., Casteleyn, L., Joas, R., Van Tongelen, B. 2007. Online integrated solution to collect data, generate information and manage events in the human biomonitoring field. Int. J. Hyg. Environ. Health. 210, 3-4.

Schindler, B., Esteban, K., Koch, M., Castano, A., Koslitz, S., Cañas, A., Casteleyn, L. Kolossa-Gehring, M., Schwedler, G., Schoeters, G., Den Hond, E., Sepai, O., Exley, K., Bloemen, L., Horvat, M., Knudsen, L.E., Joas, A., Joas, R., Biot, P., Aerts, D., Lopez, A., Huetos, O., Katsonouri, A., Maurer-Chronakis, K., Kasparova, L., Vrbík, K., Rudnai, P., Naray, M., Guignard, C., Fischer, M.E., Ligocka, D., Janasik, B., Reis, M.F., Namorado, S., Pop, C., Dumitrascu, I., Halzlova, K., Fabianova, E., Mazej, D. Tratnik, J.S., Berglund, M. Jönsson, B., Lehmann, A., Crettaz, P., Frederiksen, H. Nielsen, F., McGrath, H., Nesbitt, I., De Cremer, K., Vanermen, G., Koppen, G. Wilhelm, M., Becker, K., Angerer, J., 2014. The European COPHES/DEMOCOPHES project: towards transnational comparability and reliability of human biomonitoring results. Int. J. Hyg. Environ. Health 217 (6), 653-666.

Schoeters, G., Den Hond, E., Colles, A., Loots, I., Morrens, B., Keune, H., Bruckers, L., Nawrot, T., Sioen, I., De Coster, S., Van Larebeke, N., Nelen, V., Van de Mieroop, E., Vrijens, J., Croes, K., Goeyens, K., Baeyens, W., 2012. Concept of the Flemish human biomonitoring programme. Int. J. Hyg. Environ. Health 215, 102-108.

Silins, I., Hogberg, J., 2011. Combined toxic exposures and human health: biomarkers of exposure and effect. Int. J. Environ. Res. Public Health 8, 629-647.

Stayner, L.T., Pedersen, M., Patelarou, E., Decordier, I., Vande Loock, K., Chatzi, L., Espinosa, A., Fthenou, E., Nieuwenhuijsen, M.J., Gracia-Lavedan, E., Stephanou, E.G., Kirsch-Volders, M., Kogevinas, M., 2014. Exposure to brominated trihalomethanes in water during pregnancy and micronuclei frequency in maternal and cord blood lymphocytes. Environ. Health Perspect. 122, 100-106.

Vineis, P., van Veldhoven, K., Chadeau-Hyam, M., Athersuch, T.J., 2013. Advancing the application of omics-based biomarkers in environmental epidemiology. Environ. Mol. Mutagen. 54, 461-467.

Viso, A.C., Casteleyn, L., Biot, P., Eilstein, D., 2009. Human biomonitoring programmes and activities in the European Union. J. Epidemiol. Community Health 63, 623-624.

Vrijheid, M., Slama, R., Robinson, O., Chatzi, L., Coen, M., van den Hazel, P., Thomsen C., Wright, J., Athersuch, T.J., Avellana, N., Basagana, X., Brochot, C., Bucchini, L., Bustamante, M., Carracedo, A., Casas, M., Estivill, X., Fairley, L., van Gent, D. Gonzalez, J.R., Granum, B., Grazuleviciene, R., Gutzkow, K.B., Julvez, J., Keun, H. C., Kogevinas, M., McEachan, R.R., Meltzer, H.M., Sabido, E., Schwarze, P.E. Siroux, V., Sunyer, J., Want, E.J., Zeman, F., Nieuwenhuijsen, M.J., 2014. The human early-life exposome (HELIX): project rationale and design. Environ. Health Perspect. 122, 535-544. 